\title{
TRABECULECTOMY IN DIABETIC PATIENTS WITH GLAUCOMA
}

\author{
CHARLES E. HUGKULSTONE, LINDSEY F. SMITH and STEPHEN A. VERNON \\ Nottingham
}

\begin{abstract}
SUMMARY
Forty-one eyes of $\mathbf{4 1}$ patients with diabetes mellitus who underwent trabeculectomy over a 4-year period were compared with 41 age- and sex-matched controls, who were also matched for date of operation and surgical technique. The two groups were comparable for glaucoma diagnoses, duration of glaucoma before admission and number of ocular hypotensive medications. The intraocular pressures at diagnosis and on admission were similar. Post-operative complications were equally frequent. The mean intraocular pressure at 6 months was significantly lower in the control group, and fewer diabetic patients achieved either an intraocular pressure $<21 \mathrm{mmHg}$ or successful drainage (defined as an intraocular pressure $<21 \mathrm{mmHg}$ on no treatment) at 6 months and at the final visit, after similar periods of follow-up. Trabeculectomy in diabetic patients with pre-existing retinopathy resulted in a significantly higher intraocular pressure at 6 months than when no retinopathy was present.
\end{abstract}

Since its introduction in $1968,{ }^{1}$ trabeculectomy has become the procedure of choice for glaucoma. Subsequent reports have documented its success in the control of intraocular pressure (IOP), ${ }^{2-8}$ and it has been shown to offer better control of glaucoma, in terms of IOP and progressive field loss, when used as primary treatment. ${ }^{9,10}$ However, failure does occur, and is characterised by a marked inflammatory response in the conjunctival dermis and Tenon's capsule in early (less than 6 months) failure. ${ }^{11}$ This has been linked to the effects of prolonged topical therapy, ${ }^{10}$ which has been shown to increase the number of tissue inflammatory cells. ${ }^{12}$

In a study of factors affecting IOP control after three different drainage procedures (posterior lip sclerectomy, trabeculectomy and 'guarded keratostomy') in 194 eyes of 158 patients, Levene dismissed diabetes as a factor in pressure control. ${ }^{13}$ However, there were only 17 eyes from patients with diabetes in his study and there is no mention

Correspondence to: Mr. C. E. Hugkulstone, FRCSEd, FCOphth, Academic Unit of Ophthalmology, University Hospital, Nottingham NG7 2UH, UK. of their distribution between the three surgical procedures, which were performed consecutively without random allocation. There is very little in the literature on trabeculectomy in diabetic patients. We present here the first such study and compare the results with a matched, non-diabetic control group.

\section{METHODS}

Patients with diabetes mellitus who had undergone trabeculectomy between 1 April 1987 and 31 March 1991 were identified from theatre records. These were age- and sexmatched (again from the theatre registers) with non-diabetic patients who had had trabeculectomy at the same time. They were also matched for surgical technique (limbus- or fornix-based conjunctival flaps being the only major difference).

The notes for these two groups were then reviewed. Glaucoma diagnosis and date, duration of disease before admission (in months) and treatment on admission were recorded. Anaesthetic technique and post-operative complications were noted. IOPs were recorded at diagnosis, on admission, at the first post-operative visit, at 6 months following surgery and at the final visit, as were the respective number of ocular hypotensive medications. Follow-up (in months) was defined as the time from surgery until the final visit.

For the diabetic group, the type of diabetes and the year of diagnosis were also noted, as was the treatment regime. The presence of retinopathy and prior laser therapy was recorded.

If both eyes of any patient underwent trabeculectomy during the study period, then only the first eye treated was included in this report: Statistical analysis was performed using the unpaired $t$-test on mean values (except for the number of medications, which was analysed with the Mann-Whitney test). Frequencies were compared with either the chi-squared test (with Yates' correction for small numbers for fourfold tables) or Fisher's exact probability test. Results are given as mean (SD), unless otherwise noted.

\section{RESULTS}

Forty-three diabetic patients who had undergone trabecu- 
Table I. Glaucoma diagnoses for all patients (analysis 1)

\begin{tabular}{lcr}
\hline & Controls & Diabetics \\
\hline Chronic open angle & $34(83 \%)$ & $27(66 \%)$ \\
Chronic narrow angle & $4(10 \%)$ & $6(15 \%)$ \\
Rubeotic & 0 & $4(10 \%)$ \\
Other & $3(7 \%)$ & $4(10 \%)$ \\
\hline
\end{tabular}

lectomy were initially identified. However, 2 case notes proved untraceable, leaving 41 patients in this report. There were 15 women and 26 men and their mean age was 67.3 (8.7) years. These were compared with a control group of 41 non-diabetic patients (15 women and 26 men) with a similar mean age of 67.0 (7.2) years.

\section{Analysis 1}

Analysis 1 involved all patients. There was no difference between the two groups for duration of glaucoma before admission (32.8 (38.0) months for the diabetic group versus 37.3 (45.0) months for the controls). Mean follow-up was also comparable (29.7 (14.2) months and 32.5 (12.8) months, respectively). The glaucoma diagnoses for the two groups are detailed in Table I, and show no significant difference.

Similar numbers in each group underwent surgery under local anaesthesia (23 (56\%) in the diabetic group and 24 (59\%) in the control group). An absence of postoperative complications was equally frequent (11 (27\%) and $9(22 \%)$, respectively). Twenty-five (61\%) of the diabetic trabeculectomies developed a post-operative hyphaema and 12 (29\%) had shallow or flat anterior chambers. These proportions were not dissimilar to those found in the control group (24 (59\%) and 18 (44\%), respectively).

The mean IOPs and number of glaucoma medications for the two groups are shown in Table II. There was no significant difference between the two groups regarding their mean diagnostic and admission IOPs, or the number of treatments on admission. The number of post-operative treatments was also similar. However, the control group had lower mean IOPs at both the first post-operative visit and at 6 months $(p<0.02$ and $p<0.05$, respectively). Although the mean values at the final visit were $2.3 \mathrm{mmHg}$ lower in the control group, this did not quite reach statistical significance $(p=0.11)$. There were no differences between diabetics and controls for either the mean absolute or mean percentage fall in IOP, from either the diagnostic or the admission values.

Table II. Mean (SD) intraocular pressures (IOP) and number of treatments for all patients (analysis 1)

\begin{tabular}{|c|c|c|c|c|c|c|}
\hline & \multicolumn{4}{|c|}{ Controls } & \multicolumn{2}{|c|}{ Diabetics } \\
\hline & \multicolumn{2}{|c|}{$\mathrm{IOP}(\mathrm{mmHg})$} & \multicolumn{2}{|c|}{$\begin{array}{l}\text { No. of } \\
\text { treatments }\end{array}$} & \multirow{2}{*}{$\frac{\mathrm{IOP}(\mathrm{mmHg})}{37.6(12.6)}$} & $\begin{array}{l}\text { No. of } \\
\text { treatments }\end{array}$ \\
\hline Dia & 33.9 & (7. & 0 & $((\mathrm{C}) \cdot)$ & & (0) \\
\hline Admission & 25.9 & $(7.3)$ & 1.8 & $(0.8)$ & $30.7(14.0)$ & $2.0 \quad(0.7)$ \\
\hline 1st post-op. & 12.4 & $(6.5)$ & 0 & (0) & $16.7 \quad(8.5)$ & (0) \\
\hline 6 months & 13.9 & $(4.9)$ & 0.1 & $(0.2)$ & $17.2(8.6)$ & $0.2 \quad(0.6)$ \\
\hline Final visit & 14.5 & $(4.3)$ & 0.2 & $(0.4)$ & $16.8 \quad(8.4)$ & $0.3 \quad(0.6)$ \\
\hline
\end{tabular}

Table III. Number (percentage) of patients with an IOP $<21 \mathrm{mmHg}$ and successful surgery (IOP $<21 \mathrm{mmHg}$ on no treatment)

\begin{tabular}{|c|c|c|c|c|}
\hline \multirow[b]{3}{*}{ Controls $(n=41)$} & \multicolumn{2}{|c|}{ IOP $<21 \mathrm{mmHg}$} & \multicolumn{2}{|c|}{ Successful surgery } \\
\hline & 6 months & Final visit & 6 months & Final visit \\
\hline & $40 \quad(98 \%)$ & $39(95 \%)$ & $38 \quad(93 \%)$ & $34 \quad(83 \%)$ \\
\hline $\begin{array}{l}\text { All diabetics } \\
(n=41) \\
(\text { analysis } 1)\end{array}$ & $30 \quad(73 \%)$ & $31 \quad(76 \%)$ & $28 \quad(68 \%)$ & $25 \quad(61 \%)$ \\
\hline $\begin{array}{l}\text { Diabetics minus } \\
\text { rubeosis }(n=37) \\
(\text { analysis } 2)\end{array}$ & $27(73 \%)$ & $29(78 \%)$ & $26(70 \%)$ & $24(65 \%)$ \\
\hline
\end{tabular}

The numbers of patients who did not require postoperative glaucoma treatment to the operated eye were similar between the two groups in this study (34 (83\%) at 6 months and $33(81 \%)$ at the final visit of the diabetic group versus $39(95 \%)$ and $35(85 \%)$, respectively, of the contròl group).

Significantly fewer diabetic patients had an IOP $<21 \mathrm{mmHg}$ at 6 months $(p=0.003)$ and at the final visit $(p=0.026)$. Success of the trabeculectomy (defined as an IOP $<21 \mathrm{mmHg}$ on no medication) was significantly less frequent in diabetics than in controls at 6 months and at the final visit ( $p=0.011$ and $p<0.05$ respectively) (Table III).

The numbers of patients who had undergone prior intraocular surgery or argon laser trabeculoplasty before trabeculectomy were similar in the two groups (13 $(32 \%)$ of the diabetics versus 7 (17\%) of the controls). There was no significant difference in the distribution of these patients to explain our findings, either in the proportion of patients with an IOP $<21 \mathrm{mmHg}$ at 6 months and at the final visit, or in the frequency of a successful trabeculectomy at 6 months and at the final visit.

\section{Analysis 2}

Analysis 2 excludes the 4 diabetic patients with rubeotic glaucoma. When compared with the control group, no significant differences were found as regards their age, duration of glaucoma before admission and follow-up. The proportion of operations performed under local anaesthesia and the frequency of complications remained similar between the two groups.

Their mean IOPs and number of treatments are detailed in Table IV. No difference was found in the number of treatments throughout the study. The mean IOP at 6 months post-operatively was significantly lower in the control group $(p<0.05)$. Otherwise, there were no differences in mean IOP, nor in the mean absolute and mean percentage fall in IOP from either diagnostic or admission values.

Table IV. Mean (SD) IOPs and number of treatments in the diabetic group, with rubeotic glaucoma excluded (analysis 2)

\begin{tabular}{lcccc}
\hline & \multicolumn{2}{c}{ IOP $(\mathrm{mmHg})$} & \multicolumn{2}{c}{ No. of treatments } \\
\hline Diagnosis & 35.0 & $(8.8)$ & 0 & $(0)$ \\
Admission & 29.2 & $(12.6)$ & 2.0 & $(0.7)$ \\
1st post-op. & 15.1 & $(7.3)$ & 0 & $(0)$ \\
6 months & 17.2 & $(8.9)$ & 0.2 & $(0.6)$ \\
Final visit & 16.2 & $(8.2)$ & 0.3 & $(0.6)$ \\
\hline
\end{tabular}


Table V. Glaucoma diagnoses for diabetic patients with and without pre-existing retinopathy (excluding rubeosis) (analysis 3 )

\begin{tabular}{lrllc}
\hline & \multicolumn{2}{c}{ No retinopathy } & \multicolumn{2}{c}{ Retinopathy } \\
\hline Chronic open angle & 23 & $(74 \%)$ & 4 & $(67 \%)$ \\
Chronic narrow angle & 5 & $(16 \%)$ & 1 & $(17 \%)$ \\
Other & 3 & $(10 \%)$ & 1 & $(17 \%)$ \\
\hline
\end{tabular}

The number of patients in this analysis of diabetic trabeculectomies who had an IOP $<21 \mathrm{mmHg}$ at 6 months and at the final visit was still less than in the control group ( $p=0.004$ and $p=0.059$, respectively). Fewer successful trabeculectomies were also found in this subgroup at 6 months $(p=0.021)$, but at the final visit the difference did not reach statistical significance $(0.5>p>0.1)$ (Table III).

\section{Analysis 3}

Analysis 3 divides the diabetic group (excluding those with rubeosis) into two, based on the presence or absence of retinopathy before the trabeculectomy was performed. Thirty-one had no retinopathy and 6 had pre-existing retinopathy. The retinopathy subgroup was comparable in age to those without retinopathy (62.5 (9.1) versus 68.9 (8.5) years, respectively). The duration of diabetes was longer in the subgroup with retinopathy $(20.3$ (10.1) versus 7.0 ( 8.1$)$ years, $p<0.002$ ), as would be expected. The mean duration of glaucoma before surgery was longer in those with retinopathy $(60.0(60.4)$ months) than in those without retinopathy (31.4 (32.5) months), but this was not statistically significant. The follow-up after surgery was similar in these two subgroups (28.7 (13.6) versus 31.5 (14.3) months, respectively).

The distribution of glaucoma diagnoses is shown in Table V, and Table VI documents the mean IOPs and number of treatments for these two subgroups. The mean IOPs were not significantly different at diagnosis, on admission, or at the first post-operative visit. However, by 6 months the retinopathy subgroup had a significantly higher mean IOP $(p<0.05)$. At the final visit there was still a $6 \mathrm{mmHg}$ difference, although this did not achieve statistical significance $(p=0.1)$. No differences were found in the number of treatments at any time.

\section{Analysis 4}

Analysis 4 looked only at those patients with chronic open angle glaucoma. No differences were found between the

Table VI. Mean (SD) IOPs and number of treatments in diabetic patients with and without pre-existing retinopathy (analysis 3)

\begin{tabular}{|c|c|c|c|c|c|c|}
\hline \multirow[b]{3}{*}{ Diagnosis } & \multicolumn{4}{|c|}{ No retinopathy } & \multicolumn{2}{|c|}{ Retinopathy } \\
\hline & \multicolumn{2}{|c|}{$\mathrm{IOP}(\mathrm{mmHg})$} & \multicolumn{2}{|c|}{$\begin{array}{l}\text { No. of } \\
\text { treatments }\end{array}$} & $\mathrm{IOP}(\mathrm{mmHg})$ & $\begin{array}{c}\text { No. of } \\
\text { treatments }\end{array}$ \\
\hline & 34.4 & (8.7) & 0 & $(0$ & $37.8 \quad(9.0)$ & $(0)$ \\
\hline Admission & 28.2 & (12.3) & 2.0 & $(0.7)$ & 34.5 (14.1) & 2.0 \\
\hline $1 \mathrm{st} p$ & 14.9 & (7.6) & 0 & $(0)$ & $16.3(5.9)$ & (0) \\
\hline 6 mont & 15.9 & (6.2) & 0.2 & $(0.6)$ & 24.0 (16.7) & $0.3 \quad(0.8)$ \\
\hline Final visit & 15.2 & (5.0) & 0.3 & $(0.7)$ & 21.2 (13.7) & $(0)$ \\
\hline
\end{tabular}

Table VII. Mean (SD) IOPs and number of treatments in patients with chronic open angle glaucoma (analysis 4)

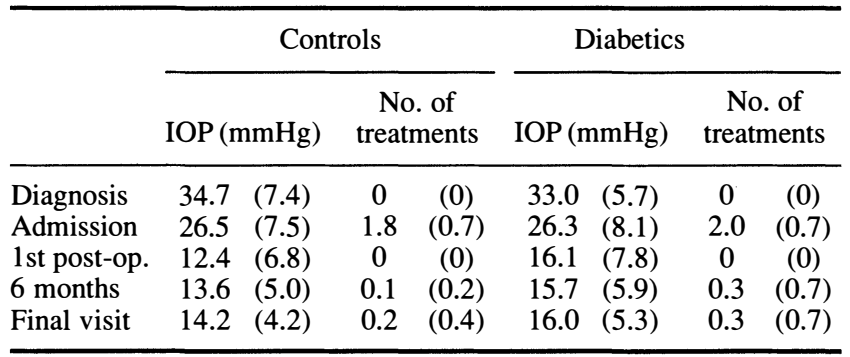

two groups as regards mean age (70.3 (7.6) years for diabetics versus 66.6 (7.6) years for controls), duration of disease before trabeculectomy (35.9 (31.1) months and 40.7 (47.8) months, respectively) or follow-up (31.8 (15.2) months and 31.9 (12.6) months, respectively). Similar numbers of patients in each group had undergone prior surgery $(6(22 \%)$ in the diabetic group and $3(9 \%)$ in the control group).

Their mean IOPs and number of ocular hypotensive medications are shown in Table VII. No significant differences in mean IOP were found between the two groups, apart from at the first post-operative visit $(p=0.053)$, although the diabetic group had consistently higher postoperative values. The mean number of treatments was similar between the two groups. Fewer diabetics had an IOP $<21 \mathrm{mmHg}$ at 6 months and at the final visit $(p=0.05$ for both). Controls again had higher success rates, although these did not achieve statistical significance ( $p=0.15$ at 6 months and $p>0.5$ at the final visit) (Table VIII).

During this study, 2 patients underwent repeat trabeculectomy and 1 had subsequent argon laser trabeculoplasty; all 3 were from the diabetic group. However, 3 control patients required cataract extraction after trabeculectomy, as did 1 diabetic. Although interesting, these frequencies were not statistically significant. No patient developed a bleb abscess or endophthalmitis.

\section{DISCUSSION}

This is the first study to investigate the outcome of trabeculectomy in diabetic patients with glaucoma. The results are compared with a control group matched for age, sex and time of operation. Although previous reports have demonstrated comparable results in IOP control for drainage surgery with either a limbus- or fornix-based conjunctival flap, ${ }^{14,15}$ we have also matched diabetic patients and their controls for surgical technique. Matching was performed through theatre records, and it is interesting

Table VIII. Number (percentage) of patients with an IOP $<21 \mathrm{mmHg}$ and successful surgery (IOP $<21 \mathrm{mmHg}$ on no treatment) for patients with chronic open angle glaucoma (analysis 4)

\begin{tabular}{|c|c|c|c|c|c|c|}
\hline & \multicolumn{3}{|c|}{ Controls $(n=34)$} & \multicolumn{3}{|c|}{ Diabetics $(n=27)$} \\
\hline & IOP $<2$ & $\mathrm{mmHg}$ & Success & IOP $<2$ & $\mathrm{mmHg}$ & Success \\
\hline 6 months & 33 & $(97 \%)$ & $31 \quad(91 \%)$ & 21 & $(78 \%)$ & $20 \quad(74 \%)$ \\
\hline Final visit & t 33 & $(97 \%)$ & $29(85 \%)$ & 21 & $(78 \%)$ & $18 \quad(67 \%)$ \\
\hline
\end{tabular}


that other variables, such as diagnostic IOP, number of treatments pre-operatively and duration of glaucoma are comparable between the two groups.

Our two groups in analysis 1 were essentially similar in glaucoma diagnoses. Previous reports of trabeculectomy have not shown any difference in the effectiveness of trabeculectomy for different glaucoma diagnoses..$^{2-4,7,13}$ However, Levene found that aphakia adversely influenced IOP control, ${ }^{13}$ although others have achieved good results in aphakic patients. ${ }^{2,7}$ The obvious difference in our study was that 4 patients in the diabetic group had rubeotic glaucoma, and the outcome of drainage surgery alone in these patients is poor. ${ }^{2,716}$ It has been suggested that panretinal photocoagulation should be performed first to induce regression of the rubeosis, before proceeding to trabeculectomy. ${ }^{17}$ However, even with the rubeotic patients excluded (analysis 2), our results were not affected.

With mounting evidence of the adverse effect of topical medications, both as regards their number and their duration, ${ }^{10,12}$ it is important to note that our two study groups in all analyses were comparable in terms of both number of medications and their duration of use, as assessed by the length of time from diagnosis to admission for surgery. Previous argon laser trabeculoplasty has been suggested as a risk factor in the development of Tenon's capsule cysts. ${ }^{18}$ This factor was equally distributed between the two groups and thus should not influence the outcome of drainage surgery.

Although our study is retrospective, with the biases that may arise from such a study, we feel that the two groups are comparable for the important risk factors known to affect the results of trabeculectomy, the major difference between the two groups being the presence of diabetes mellitus. However, we were unable to assess the severity of the glaucoma as evidenced by the visual field defect, although this has been suggested to play little part in the outcome of surgery. ${ }^{10}$ Diagnostic IOPs were similar, although it has been reported that a first trabeculectomy will reduce the IOP to between 16 to $20 \mathrm{mmHg}$, irrespective of the initial IOP. ${ }^{7,19}$

We have found a lower incidence of success following trabeculectomy in diabetics in the first 6 months after surgery, either absolute success (an IOP $<21 \mathrm{mmHg}$ on no treatment, analyses 1 and 2) or relative success (an IOP $<21 \mathrm{mmHg}$ with and without treatment, analyses 1,2 and 4). Similarly, the controls have better success rates at the final visit, after comparable follow-up. In addition, diabetic patients has significantly higher mean IOPs at 6 months than did the controls (analyses 1 and 2). That the final IOP in the diabetic groups did not reach a level that was statistically different from the controls may well be due to the relatively small numbers in this study. With 'target pressures' increasing in popularity, a difference of 2-3 $\mathrm{mmHg}$ may be considered clinically significant. The results of our control group are comparable to those in previous studies which followed conventional management, ${ }^{2,4,6-8,13}$ although not quite as good as when drainage surgery is performed as the primary treatment. ${ }^{10}$
The majority of trabeculectomy failures occur in the first 6 months, ${ }^{7,13}$ and are characterised by a marked inflammatory response in the conjunctival dermis and Tenon's capsule. ${ }^{11}$ An excessive breakdown in the bloodaqueous barrier in the first 3 months following cataract surgery has been linked to diabetes,$^{20}$ as has an increased incidence of post-operative inflammation assessed clinically. ${ }^{21}$ It could be expected that similar effects occur in diabetics following trabeculectomy, and this may be the explanation for our findings. This hypothesis is supported by the fact that the level of aqueous protein in diabetic eyes is higher in the presence of retinopathy and is related to the severity of the retinopathy, ${ }^{22}$ and we have demonstrated lower post-operative IOPs in diabetics without retinopathy when compared with those with pre-existing retinopathy (analysis 3).

Non-steroidal anti-inflammatory agents used in conjunction with topical steroids have been shown to produce less breakdown of the blood-aqueous barrier following cataract surgery than topical steroids alone. ${ }^{23}$ In the light of our findings, their use in diabetic patients undergoing trabeculectomy may improve the operation's success rate. Alternatively, the use of per-operative anti-metabolites, such as 5-fluorouracil (P. T. Khaw et al., presented at the Glaucoma Group Meeting, November 1992) could be considered, particularly when diabetic retinopathy is present.

Our grateful thanks are due to Messrs. N. R. Galloway, S. M. Haworth, P. Jacobs, D. Knight Jones and S. N. Rizk for kindly allowing us to study patients under their care.

Key words: Diabetes mellitus, Glaucoma, Intraocular pressure, Trabeculectomy.

\section{REFERENCES}

1. Cairns JE. Trabeculectomy: preliminary report of a new method. Am J Ophthalmol 1968;66:673-9.

2. Watson PG, Barnett F. Effectiveness of trabeculectomy in glaucoma. Am J Ophthalmol 1975;79:831-45.

3. Wilson P. Trabeculectomy: long-term follow-up. Br J Ophthalmol 1977;61:535-8.

4. D'Ermo F, Bonomi L, Doro D. A critical analysis of the long-term results of trabeculectomy. Am J Ophthalmol 1979;88:829-35.

5. Jerndal T, Lundstrom M. 330 trabeculectomies: a long time study $\left(3-5 \frac{1}{2}\right.$ years). Acta Ophthalmol (Copenh) 1980;58:947-56.

6. Zaidi AA. Trabeculectomy: a review and 4-year follow-up. Br J Ophthalmol 1980;64:436-9.

7. Mills KB. Trabeculectomy: a retrospective long-term follow-up of 444 cases. Br J Ophthalmol 1981;65:790-5.

8. Watson PG, Jakeman C, Ozturk M, Barnett MF, Bamett F, Khaw KT. The complications of trabeculectomy: a 20 -year follow-up. Eye 1990;4:425-38.

9. Jay JL, Murray SB. Early trabeculectomy versus conventional management in primary open angle glaucoma. $\mathrm{Br} \mathrm{J}$ Ophthalmol 1988;72:881-9.

10. Lavin MJ, Wormald RPL, Migdal CS, Hitchings RA. The influence of prior therapy on the success of trabeculectomy. Arch Ophthalmol 1990;108:1543-8.

11. Hitchings RA, Grierson I. Clinicopathological correlation in eyes with failed fistulizing surgery. Trans Ophthalmol Soc UK 1983;103:84-8. 
12. Sherwood MB, Grierson I, Millar L, Hitchings RA. Longterm morphologic effects of antiglaucoma drugs on the conjunctiva and Tenon's capsule in glaucomatous patients. Ophthalmology 1989;96:327-35.

13. Levene RZ. Glaucoma filtering surgery: factors that determine pressure control. Trans Am Ophthalmol Soc 1984;82:282-99.

14. Shuster JN, Krupin T, Kolker AE, Becker B. Limbus- v. fornix-based conjunctival flap in trabeculectomy: a long-term randomized study. Arch Ophthalmol 1984;102:361-2.

15. Traverso CE, Tomey KF, Antonios S. Limbal- vs fornixbased conjunctival trabeculectomy flaps. Am J Ophthalmol 1987;104:28-32.

16. Ridgway AEA. Trabeculectomy: a follow-up study. Br J Ophthalmol 1974;58:680-6.

17. Flanagan DW, Blach RK. Place of panretinal photocoagulation and trabeculectomy in the management of neovascular glaucoma. Br J Ophthalmol 1983;67:526-8.

18. Feldman RM, Gross RL, Spaeth GL, et al. Risk factors for the development of Tenon's capsule cysts after trabeculectomy. Ophthalmology 1989;96:336-41.

19. Jay JL, Murray SB. Characteristics of reduction of intraocular pressure after trabeculectomy. $\mathrm{Br} \mathbf{J}$ Ophthalmol 1980;64:432-5.

20. Ferguson VMG, Spalton DJ. Continued breakdown of the blood-aqueous barrier following cataract surgery. $\mathrm{Br} \mathrm{J}$ Ophthalmol 1992;76:453-6.

21. Cunliffe IA, Flanagan DW, George NDL, Aggarwaal RJ, Moore AT. Extracapsular cataract surgery with lens implantation in diabetics with and without proliferative retinopathy. Br J Ophthalmol 1991;75:9-12.

22. Oshika T, Kato S, Funatsu H. Quantitative assessment of aqueous flare intensity in diabetes. Graefes Arch Clin Exp Ophthalmol 1989;227:518-20.

23. Sanders DR, Kraff M. Steroidal and nonsteroidal antiinflammatory agents: effect on postsurgical inflammation and blood-aqueous humor barrier breakdown. Arch Ophthalmol 1984;102:1453-6. 